\title{
Predictive value of pulse oximetry for the development of fetal acidosis
}

\author{
Andreas Nonnenmacher*, Hartmut Hopp and \\ Joachim Dudenhausen \\ Department of Obstetrics, Charité - Universitätsmedizin \\ Berlin, Berlin, Germany
}

\begin{abstract}
Aims: To determine the predictive value of fetal pulse oximetry (FPO) for the development of fetal acidosis in cases of non-reassuring fetal heart rate (FHR).

Methods: In a prospective observational study, pulse oximetry monitoring was examined in cases of non-reassuring FHR during singleton cephalic delivery at 36-42 weeks' gestation. The study examined whether fetal arterial oxygen saturation $\left(\mathrm{FSpO}_{2}\right)$ values $<30 \%$ for at least 10 min during the last $60 \mathrm{~min}$ before delivery increase the risk of fetal acidosis. The predictive reliability of this algorithm and the correlation to fetal acidosis [umbilical artery $\mathrm{pH}(\mathrm{UApH})$ $<7.15$ ] were analyzed.

Results: We included 101 patients with non-reassuring FHR during delivery. The incidence of fetal acidosis was significantly higher when $\mathrm{FSpO}_{2}$ values $<30 \%$ were recorded for at least $10 \mathrm{~min}(\mathrm{P}=0.0)$. An $\mathrm{UApH}<7.15$ was reliably excluded with a negative predictive value of $98.7 \%$ and detected with a sensitivity of $92.9 \%$.

Conclusions: A low pulse oximetry oxygen saturation $<30 \%$ for at least 10 min correlates highly with fetal acidosis in cases of non-reassuring FHR. FPO reliably excludes moderate to advanced acidosis and can reduce the frequency of fetal blood analysis (FBA) in cases of non-reassuring cardiotocography (CTG).
\end{abstract}

Keywords: Fetal acidosis; fetal pulse oximetry; intrapartum fetal monitoring; non-reassuring fetal heart rate.

\section{Introduction}

The aim of intrapartum electronic fetal monitoring is to detect high-risk conditions early enough to prevent damage to the fetus. However, cardiotocography (CTG) with nonreassuring fetal heart rate (FHR) patterns very often corre-

\footnotetext{
*Corresponding author:

Dr. Andreas Nonnenmacher

Charité Klinik für Geburtsmedizin

Campus Benjamin Franklin

Hindenburgdamm 30

12200 Berlin, Germany

Tel.: +49-30 8445648110

Fax: +49-30 84454477

E-mail: Andreas.nonnenmacher@charite.de
}

spond to physiological changes [13]. With high sensitivity but low specificity of the monitoring method, false-positive CTG results would lead to an increase in unjustified operative deliveries $[1,6,18]$. The high false-positive rate of intrapartum CTG can be reduced by performing fetal blood analysis (FBA). Combined intrapartum monitoring (CTG plus FBA) with determination of the fetal acid-base status achieves the necessary diagnostic reassurance in cases of non-reassuring FHR [5]. Investigations have demonstrated a reduction in hypoxia-related mortality [19], neonatal convulsions [1] and avoidable operative deliveries when FBA is indicated [8]. The procedure has not gained general acceptance in many countries because it requires additional expertise, yields random results necessitating repeated fetal blood sampling, and is a complex and invasive method. There is an ongoing search for a complementary intrapartum monitoring method that adds valuable information like fetal pulse oximetry (FPO) oxygen saturation [4, 17]. Registered simultaneously with the CTG, FPO with good signal quality confirms FHR changes associated with fetal hypoxemia. The value of this monitoring procedure depends on its reliability in detecting or excluding fetal acidosis in cases of non-reassuring FHR. Simultaneous monitoring with FPO could have the advantage of reducing the need for complex FBA without increasing the risk of fetal damage due to undetected anoxic phases. Fetal arterial oxygen saturation $\left(\mathrm{FSpO}_{2}\right)$ measured by pulse oximetry has a critical threshold value of $30 \%$ according to experimental studies and clinical data obtained using the N-400 fetal pulse oximeter and the FS14B fetal sensor (Nellcor, Pleasanton, CA, USA) [12, 15]. Fetal acidosis may be expected if $\mathrm{FSpO}_{2}$ remains below $30 \%$ for a longer period of time $[6,10,16]$. A major problem associated with FPO registration - the poor application stability and high signal loss of the now discontinued FS14 fetal sensor (Nellcor system) - has been overcome. The FetalSAT pulse oximeter (NONIN Medical Inc., Plymouth, MN, USA) records reliable $\mathrm{FSpO}_{2}$ data in over $90 \%$ of the registered time period [9]. The third FPO system, OB Scientific (Germantown, WI, USA) uses a tongue-depressor-shaped sensor that is placed on the fetal body. Postductal $\mathrm{FSpO}_{2}$ values obtained from this localization are lower than oxygen saturation measurements in cases of breech presentation [11].

Using FPO as a complementary technique in combined intrapartum monitoring, this study examined whether the $\mathrm{FSpO}_{2}$ threshold value of $30 \%$ determined for the N-400 pulse oximeter can also be used for the FetalSAT system to reliably detect or exclude the presence of fetal acidosis. Fetal hypoxemia was assumed at $\mathrm{FSpO}_{2}$ values below $30 \%$ for at least $10 \mathrm{~min}$ during the last $60 \mathrm{~min}$ before delivery. Despite the different measuring systems and sensors, the significance 
of threshold value analysis for detecting or excluding fetal acidosis was tested at different times, first with the Nellcor system and then with the FetalSAT system.

\section{Methods}

A prospective observational study was performed to examine the value of intrapartum FPO in cases of non-reassuring CTG. It included women with a single fetus in cephalic presentation at $36-42$ weeks' gestation and cervical dilatation $\geq 3 \mathrm{~cm}$. FPO was used as a complementary technique in combined intrapartum monitoring. When FHR findings constituted an indication for FBA, the sensor was applied after obtaining informed consent from the mother. Continuous measurement was performed by appropriately trained obstetricians without blinding. Simultaneously registered $\mathrm{FSpO}_{2}$ values in cases of non-reassuring FHR [13] were compared with the umbilical artery $\mathrm{pH}(\mathrm{UApH})$ in a total of 119 deliveries. Intrapartum $\mathrm{FSpO}_{2}$ monitoring was evaluated in 65 traces with the N-400 fetal pulse oximeter (Nellcor, Pleasanton, CA, USA) from January 2002 to December 2004 and 54 traces with the FetalSAT system from January 2005 to December 2007. Exclusion criteria were pulse oximetry traces with a signal loss of $>20 \%$ and a registration period of $<1 \mathrm{~h}$. Obstetrical decisions in cases of nonreassuring FHR were only made in combination with the FBA and not from the pulse oximetry trace. Operative delivery was considered as indicated for persistent non-reassuring FHR patterns and fetal $\mathrm{pH}$ values at the 7.20 threshold. Long and short periods of $\mathrm{FSpO}_{2}$ values $<30 \%$ were added to obtain the total duration during the last $60 \mathrm{~min}$ before delivery. The aim was to examine whether an $\mathrm{UApH}$ of $<7.15$ is significantly associated with $\mathrm{FSpO}_{2}$ values $<30 \%$ for at least $10 \mathrm{~min}$ during the last $60 \mathrm{~min}$ before delivery and to determine the probability with which it may be predicted or excluded. For this purpose, $\mathrm{FSpO}_{2}$ values of $<30 \%$ over a period of $\geq 10$ min were examined for their sensitivity and specificity as well as their negative and positive predictive value. The data were first assessed separately for the groups monitored with the Nellcor and the FetalSAT system and then for the total group. Statistical significance was calculated by Fisher's exact test and by Spearman correlation.

\section{Results}

Assessment of registered values revealed adequate signal processing with the Nellcor N-400 pulse oximeter in 49 of 65 cases but reliable signal acquisition with the FetalSAT system in over $90 \%$ of the recording time. Intrapartum monitoring was assessed in all but two cases, which were excluded for too short a recording time (52 of 54). The incidence of cesarean delivery for dystocia (NONIN group 7.8\%) doubled in the Nellcor group (16.2\%). In cases with a non-reassuring CTG, the incidence of fetal acidosis (UApH <7.15) was significantly higher for a $\geq 10$-min period of $\mathrm{FSpO}_{2}$ values $<30 \%$ than for periods of $<10$ min during the last $60 \mathrm{~min}$ before delivery. This could be demonstrated in the single groups (Nellcor system: $\mathrm{P}=0.0002$, FetalSAT system: $\mathrm{P}=0.0)$ as well as in the overall assessment $(\mathrm{P}=0.0)$. A scatter plot shows the UApH values and the duration of $\mathrm{FSpO}_{2}$ values $<30 \%$ in 101 neonates (Figure 1). The $\mathrm{FSpO}_{2}$ values
$<30 \%$ during the last 60 min before delivery correlate significantly with the UApH values at the 0.01 level.

In the group monitored with the Nellcor system (Table 1), UApH values $<7.15$ were determined in 7 of 49 neonates. In cases with $\mathrm{FSpO}_{2}$ values $<30 \%$ for $<10 \mathrm{~min}$, an intrapartum $\mathrm{UApH}<7.15$ was seen in only one neonate with a diabetic mother (negative predictive value: 97.4\%). In six neonates with $\mathrm{UApH}$ values $<7.15$, the $\mathrm{FSpO}_{2}$ values $<30 \%$ added up to $\geq 10$ min during the last hour of delivery (sensitivity: 85.7\%). Altogether 11 of 49 neonates had $\mathrm{FSpO}_{2}$ values $<30 \%$ for at least $10 \mathrm{~min}$ during the last hour of delivery. The UApH value was $\geq 7.15$ in five cases, and the result was thus false-positive (specificity: $88.1 \%$ ). $\mathrm{SpO}_{2}$ values $<30 \%$ for $\geq 10$ min during the last hour before delivery were found to have a positive predictive value of $54.6 \%$.

In the FetalSAT group (Table 2), 7 of 52 neonates had a $\mathrm{UApH}$ value $<7.15$. $\mathrm{FSpO}_{2}$ values $\geq 30 \%$ or below $30 \%$ for $<10$ min, respectively, excluded fetal acidosis with a UApH $<7.15$ (negative predictive value: 100\%). Seven neonates with $\mathrm{FSpO}_{2}$ values $<30 \%$ for $\geq 10 \mathrm{~min}$ had UApH values $<7.15$ (sensitivity: 100\%). The test was false-positive in six cases (specificity: $86.7 \%$ ). $\mathrm{FSpO}_{2}$ values $<30 \%$ for $\geq 10$ min have a positive predictive value of $53.9 \%$.

For the total group (Table 3 ) with $\mathrm{UApH}$ values $<7.15$ in 14 neonates, $\mathrm{SpO}_{2}$ values $<30 \%$ for $\geq 10$ min showed a sensitivity of $92.9 \%$ and a negative predictive value of $98.7 \%$. The test was false-positive in 11 cases, corresponding

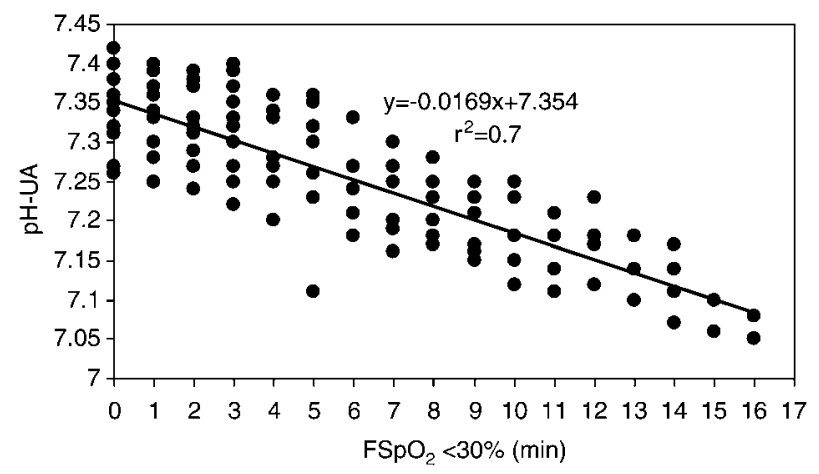

Figure 1 Scatter plot of umbilical artery $\mathrm{pH}$ values $(\mathrm{UApH})$ and the duration of $\mathrm{FSpO}_{2}$ values $<30 \%$ during the last 60 min before delivery (the Spearman correlation is significant at the 0.01 level, $\mathrm{r}=0.816)$.

Table 1 Nellcor pulse oximetry system: dependence of UApH values $<7.15$ on the duration of $\mathrm{FSpO}_{2}$ values $<30 \%$ (Fisher exact test, $\mathrm{P}=0.0002$ ).

\begin{tabular}{lccr}
\hline Nellcor & \multicolumn{2}{l}{ Test: $\mathrm{FSpO}_{2}<30 \%$} & \\
\cline { 2 - 3 }$n$ & $\begin{array}{l}\geq 10 \mathrm{~min} \\
\text { duration }\end{array}$ & $\begin{array}{c}<10 \mathrm{~min} \\
\text { duration }\end{array}$ & \\
\hline $\mathrm{UApH}<7.15$ & 6 & 1 & 7 \\
$\mathrm{UApH} \geq 7.15$ & 5 & 37 & 42 \\
Total & 11 & 38 & 49 \\
\hline
\end{tabular}

$\mathrm{UApH}$, umbilical artery $\mathrm{pH} ; \mathrm{FSpO}_{2}$, fetal arterial oxygen saturation. 
Table 2 FetalSAT pulse oximetry system: dependence of UApH values $<7.15$ on the duration of $\mathrm{FSpO}_{2}$ values $<30 \%$ (Fisher exact test, $\mathrm{P}=0.0$ ).

\begin{tabular}{llcr}
\hline FetalSAT & \multicolumn{2}{l}{ Test: $\mathrm{FSpO}_{2}<30 \%$} & \\
\cline { 2 - 3 } $\mathrm{n}=52$ & $\begin{array}{l}\geq 10 \mathrm{~min} \\
\text { duration }\end{array}$ & $\begin{array}{c}<10 \mathrm{~min} \\
\text { duration }\end{array}$ & \\
\hline $\mathrm{UApH}<7.15$ & 7 & 0 & 7 \\
$\mathrm{UApH} \geq 7.15$ & 6 & 39 & 45 \\
Total & 13 & 39 & 52 \\
\hline
\end{tabular}

$\mathrm{UApH}$, umbilical artery $\mathrm{pH} ; \mathrm{FSpO}_{2}$, fetal arterial oxygen saturation.

to a specificity of $87.4 \%$ and a positive predictive value of $54.2 \%$.

\section{Discussion}

A number of clinical studies have examined the mean fetal oxygen saturation over a defined time period in comparison with the UApH or base excess. They demonstrated good correlation as well as independence [20]. Studies examining the $\mathrm{FSpO}_{2}$ threshold value of $30 \%$ combined with an interval of at least 2 [2] or $10 \mathrm{~min}[6,17]$ have shown an increase in adverse fetal events. Prospective randomized studies on the use of FPO for intrapartum fetal monitoring have been performed with the Nellcor N-400 pulse oximeter [3, 6, 7, 10]. The primary endpoints of the studies were the rate of operative deliveries for uncertain fetal status in cases with a nonreassuring $\mathrm{CTG}$ or low $\mathrm{FSpO}_{2}$ and the overall rate of operative deliveries. The overall rate of operative deliveries did not differ between groups monitored with and without FPO, whereas the rate of operative deliveries for uncertain fetal status was significantly lower when FPO was used [6, 7, 10]. The controlled multicenter study by Garite et al. [7] achieved a $50 \%$ reduction in the rate of cesarean sections for non-reassuring CTG findings in the group with FPO, though the overall cesarean section rate remained constant. In cases of operative intervention for uncertain fetal status, the FPO group was found to have higher sensitivity and specificity for the secondary endpoints of fetal monitoring - metabolic acidosis and resuscitation of neonates [7]. Acquisition of pulse oximetry data did not reduce the rate of cesarean section or fetal acidosis in the largest controlled study conducted by Bloom et al. [3] and comprised more than 5000 monitored

Table 3 Total group: dependence of UApH values $<7.15$ on the duration of $\mathrm{FSpO}_{2}$ values $<30 \%$ (Fisher exact test, $\mathrm{P}=0.0$ ).

\begin{tabular}{|c|c|c|c|}
\hline \multirow{2}{*}{$\begin{array}{l}\text { Total } \\
\mathrm{n}=101\end{array}$} & \multicolumn{2}{|c|}{ Test: $\mathrm{FSpO}_{2}<30 \%$} & \\
\hline & $\begin{array}{l}\geq 10 \text { min } \\
\text { duration }\end{array}$ & $\begin{array}{l}<10 \text { min } \\
\text { duration }\end{array}$ & \\
\hline UApH $<7.15$ & 13 & 1 & 14 \\
\hline $\mathrm{UApH} \geq 7.15$ & 11 & 76 & 87 \\
\hline Total & 24 & 77 & 101 \\
\hline
\end{tabular}

$\mathrm{UApH}$, umbilical artery $\mathrm{pH} ; \mathrm{FSpO}_{2}$, fetal arterial oxygen saturation. deliveries. The rate of cesarean section for dystocia was as high as in the study by East et al. [6] when using the Nellcor sensor. In our study the rate for cesarean section for dystocia, was doubled in the Nellcor group compared to the NONIN group. Different durations of $\mathrm{FSpO}_{2}$ values of $<30 \%$ were used to define uncertain fetal status with low oxygen saturation in the studies mentioned. When assessing low fetal oxygen saturation by $\mathrm{FSpO}_{2}$ values $<30 \%$, some studies applied a duration of at least $10 \mathrm{~min}[6,10]$ rather than of 2 min or of an entire interval between contractions applied by others [3, 7]. With this definition, high rates of low $\mathrm{FSpO}_{2}$ were found even in cases with normal FHR patterns [3]. The FOREMOST study demonstrated a significant reduction of operative interventions in the FPO group without difference in neonatal outcome [6]. In one study, FBA was routinely applied for combined intrapartum monitoring in cases with non-reassuring FHR patterns. The use of FPO in such cases reduced the operative delivery rate and the frequency of FBA by $50 \%$ [10]. Seelbach-Göbel and Riedl [16] demonstrated that, in cases of non-reassuring CTG, the threshold value analysis $\left(\mathrm{FSpO}_{2} \leq 30 \%\right.$ for at least $\left.10 \mathrm{~min}\right)$ was able to detect (sensitivity) or exclude (negative predictive value) an UApH below 7.1 with $100 \%$ reliability. On repetition of an FBA, a significant $\mathrm{pH}$ decrease of $0.1 \mathrm{pH}$ units could also be excluded with high probability (negative predictive value of $98 \%$ ).

In the present study, the FPO recorded simultaneously with the CTG was not included in obstetrical decisions. In cases of non-reassuring CTG, FBA was used as a complementary technique to the diagnostic tests of fetal status, and delivery was operatively terminated in cases with fetal $\mathrm{pH}$ values $<7.20$. Limiting the analysis of $\mathrm{FSpO}_{2}$ values $<30 \%$ to the last $60 \mathrm{~min}$ before delivery takes into account the experience that low $\mathrm{FSpO}_{2}$ values as well as non-reassuring FHR patterns in earlier phases of labor can be corrected after improvement of the fetal oxygen supply and normalization of the intrapartum monitoring values. FPO for intrapartum fetal assessment has been restricted to the last 30 or $10 \mathrm{~min}$ before delivery in other studies as well $[10,14]$. Fetal acidosis was defined as an UApH $<7.15$ in accordance with the study by Dildy et al. [4], in which UApH values only differ at $<$ or $\geq 7.13$ with an umbilical artery oxygen saturation cut-off of $30 \%$.

Despite differences in the sensor wavelengths and measuring systems (Nellcor-FS 14B 735 and $890 \mathrm{~nm} /$ FetalSAT DualSens 661 and $905 \mathrm{~nm}$ ), analysis of the $\mathrm{FSpO}_{2}$ values for both fetal pulse oximeters showed that low fetal oxygen saturation $-\mathrm{FSpO}_{2}<30 \% \geq 10$ min during the last $60 \mathrm{~min}$ before delivery - was significantly associated with an increased incidence of fetal acidosis (UApH <7.15). Saturation monitoring with the FetalSAT system also disclosed a time-dependent rise of fetal acidosis in conjunction with values below the $\mathrm{FSpO}_{2}$ threshold of $30 \%$. In the total group, $\mathrm{FSpO}_{2}$ values $\geq 30 \%$ or below $30 \%$ for a total duration of $<10$ min, respectively, excluded fetal acidosis (UApH $<7.15$ ) with $98.7 \%$ probability (negative predictive value) and detected it in $92.9 \%$ (sensitivity). With a specificity of 
$87.4 \%$ and a positive predictive value of $54.2 \%$, sustained low $\mathrm{FSpO}_{2}$ values alone do not justify operative delivery. Here, FBA is required for promptly determine fetal status if the CTG does not suggest an acute fetal risk. The reliability of pulse oximetry monitoring is influenced by signal loss as well as by individual fetal factors, such as fetal infection, maternal diabetes (quick development of metabolic acidosis) and fetal anemia (inadequate oxygen supply despite normal $\mathrm{FSpO}_{2}$ values). To avoid false assessments, an FBA to determine the initial fetal acid-base status is recommended at the start of simultaneous pulse oximetry monitoring in cases of non-reassuring CTG [17]. Saturation measurements must be constantly checked for plausibility, and, in case of doubt, FBA should be repeated even in the presence of normal $\mathrm{FSpO}_{2}$ values.

\section{References}

[1] Alfirevic Z, Devane D, Gyte GM. Continuous cardiotocography (CTG) as a form of electronic fetal monitoring (EFM) for fetal assessment during labour. Cochrane Database Syst Rev. 2006;3:CD006066.

[2] Bloom SL, Swindle RG, McIntire DD, Levano KJ. Fetal pulse oximetry: duration of desaturation and intrapartum outcome. Obstet Gynecol. 1997;93:1036-40.

[3] Bloom SL, Spong CY, Thom E, Varner MW, Rouse DJ, Weininger $\mathrm{S}$, et al. Fetal pulse oximetry and cesarean delivery. $\mathrm{N}$ Engl J Med. 2006;355:2195-202.

[4] Dildy GA, Thorp JA, Yeast JD, Clark SL. The relationship between oxygen saturation and $\mathrm{pH}$ in umbilical blood: implications for intrapartum fetal oxygen saturation monitoring. Am J Obstet Gynecol. 1996;175:682-7.

[5] Dudenhausen JW, Luhr C, Dimer JS. Umbilical artery blood gases in healthy term newborn infants. Int J Gynecol Obstet. 1997;57:251-258.

[6] East CE, Brennecke SP, King JF, Chan FY, Colditz PB. The effect of intrapartum fetal pulse oximetry, in the presence of a nonreassuring fetal heart rate pattern, on operative delivery rates: a multicenter, randomized, controlled trial (the FOREMOST trial). Am J Obstet Gynecol. 2006;194:606-16.

[7] Garite TJ, Dildy GA, McNamara H, Nageotte MP, Boehm $\mathrm{FH}$, Dellinger EH, et al. A multicenter controlled trial of fetal pulse oximetry in the intrapartum management of nonreassuring fetal heart rate patterns. Am J Obstet Gynecol. 2000; 183:1049-58.
[8] Haverkamp AD, Orleans M, Langendoerfer S, McFee J, Murphy J, Thompson HE. A controlled trial of the differential effects of intrapartum fetal monitoring. Am J Obstet Gynecol. 1979;134:399-412.

[9] Knitza R. Fetale Pulsoxymetrie - Farewell or Comback. Geburtsh Frauenheilk. 2007;111-2.

[10] Kühnert M, Schmidt S. Intrapartum management of nonreassuring fetal heart rate patterns: a randomized controlled trial of fetal pulse oximetry. Am J Obstet Gynecol. 2004;191: 1989-95.

[11] Luttkus AK, Dimer JA, Dudenhausen JW. Are pulse oximetry findings in the breech consistent with fetal physiology? Am J Obstet Gynecol. 1998;178:S.48.

[12] Nijland R, Jongsma HW, Nijhuis J, van den Berg P, Oeseburg B. Arteriel oxygen saturation in relation to metabolic acidosis in fetal lambs. Am J Obstet Gynecol. 1995;172:810-9.

[13] Royal College of Obstetricians and Gynaecologists: The use of electronic fetal monitoring. In: Evidence-Based Clinical Guideline Number 8. London: RCOG Press; 2001. p. 12.

[14] Schmidt S, Koslowski S, Sierra F, Meyer-Wittkopf M, Heller G. Clinical usefulness of pulse oximetry in the fetus with non-reassuring heart rate pattern? J Perinat Med. 2000;28: 298-05.

[15] Seelbach-Gobel B, Butterwege M, Kühnert M, Heupel M. Fetale Reflexionspulsoxymetrie sub partu. Z Geburtsh Perinatol. 1994;198:67-71.

[16] Seelbach-Gobel B, Riedl T. Reliability of fetal pulse oximetry for the detection of fetal acidosis. Z Geburtshilfe Neonatol. 2005;209:43-50.

[17] Seelbach-Goebel B, Heupel M, Kühnert M, Butterwegge M. The prediction of fetal acidosis by means of fetal pulse oximetry. Am J Obstet Gynecol. 1999;180:73-81.

[18] Umstad MP. The predictive value of abnormal fetal heart rate patterns in early labour. Aust NZ J Obstet Gynaecol. 1993; 33:145-9.

[19] Vintzileos AM, Nochimson DJ, Guzman ER, Knuppel RA, Lake M, Schifrin BS. Intrapartum electronic fetal heart rate monitoring versus intermittent auscultation: a meta-analysis. Obstet Gynecol. 1995;85:149-55.

[20] Yam J, Chua S, Arulkumaran S. Intrapartum fetal pulse oximetry. Part 2. Clinical application. Obstet Gynecol Surv. 2000;55:173-83.

The authors stated that there are no conflicts of interest regarding the publication of this article.

Received March 3, 2009. Revised June 3, 2009. Accepted July 28, 2009. Previously published online December 3, 2009. 